\title{
О НЕКОТОРЫХ ДИСКУССИОННЫХ ВОПРОСАХ ТУРБАСЛИНСКОЙ КУЛЬТУРЫ
}

Ольга Сергеевна Белявская

независимый исследователь, Мытищи, Россия

E-mail: krapacheva.olya@mail.ru

\begin{abstract}
Аннотация. В статье рассмотрены материалы погребений, имеющих первостепенное значение для хронологии древностей Южного Приуралья эпохи Великого переселения народов и раннего средневековья. В результате анализа ременной гарнитуры и других хроноиндикаторов автором уточнена датировка исследуемых комплексов, что позволило рассмотреть ряд дискуссионных вопросов турбаслинской культуры с новых позиций. Анализ ременных принадлежностей позволил предположить, что немногочисленные группы носителей турбаслинской культуры могли появиться на территории Приуралья уже на рубеже IV-Vвв. Судя по всему, наиболее богатые позднетурбаслинские комплексы следует датировать концом VI - первой половиной VII в. С середины VII в. турбаслинская культура как «культура в чистом виде» начинает угасать, окончательно прекратив свое существование в конце VII либо на рубеже VII-VIII вв.
\end{abstract}

Ключевые слова: Южное Приуралье, раннее средневековье, турбаслинская культура, типология, хронология, ременная гарнитура

Цитирование. Белявская О.С., 2021. О некоторых дискуссионных вопросах турбаслинской культуры // Уфимский археологический вестник. Т.21, №2. C.346-357. DOI: https://doi.org/10.31833/ uav/2021.21.2.013

UDC 902.01

Submitted: 28.09 .2021

LBC 63.4

Accepted: 23.10.2021

SOME CONTROVERSIAL RESEARH QUESTIONS ABOUT THE TURBASLY CULTURE

Olga S. Belyavskaya

independent researcher, Mytishchi, Russia

E-mail: krapacheva.olya@mail.ru

\begin{abstract}
The subject of this work is the analysis of several burials that play a critical role in chronological studies of the artefacts discovered in the Southern Cis-Urals region and dated to the Great Migration period and the early Middle Ages. The current article consists of two parts. The first part of the article discusses a number of artefacts from barrow 18, burial 1 of Dezhnevsky necropolis, namely a buckle with cloisonné decoration on the front plate, a bone arrowhead and two ceramic flat bottom vessels of small and medium sizes. In the second part of the article attention focuses on studies of archaeological assemblages from the necropolises of Novo-Turbasly and Kushnarenkovo, "Chaika-1"necropolis, Novikovka burial and the female grave located on the territory of the courtyard of the Bashkir State Medical University. All of the aforementioned assemblages include numerous valuable objects, such as belt fittings of the so-called 'heraldic' type. This makes them different from most sets of artefacts discovered in the Southern Cis-Urals. Results of the archaeological analysis of the belt fittings suggest that some representatives of the Turbasly culture could have came to the territory of the Cis-Urals region as early as the turn of the $4^{\text {th }}$ th $-5^{\text {th }}$ centuries $\mathrm{AD}$. Therefore, the richest assemblages of the Turbasy culture must be dated to the end of the 6th century - the beginning of the $7^{\text {th }}$ century AD. It could be concluded that the Turbasly Culture "as it is" began to fade at this period and disappeared at the end of the $7^{\text {th }}$, at the turn of the $7^{\text {th }}-8^{\text {th }}$ centuries AD.

Keywords: Southern Cis-Urals, early Middle Ages, Turbasly culture, typology, chronology, belt fittings

Citation. Belyavskaya O., 2021. Some controversial research questions about the Turbasly culture. Ufimskij arkheologicheskiy vestnik [The Ufa Archaeological Herald]. Vol.21, no.2, pp. 346-357. (In Russ.). DOI: https://doi. org/10.31833/uav/2021.21.2.013
\end{abstract}

\section{Введение}

Памятники турбаслинской культуры, выделенной Н.А. Мажитовым [Мажитов, 1968. С.6571; Мажитов, 1977. С.93-100; Мажитов, 1981. С.23-28] и в дальнейшем подробно исследованной Ф.А.Сунгатовым [Сунгатов, 1998], локализуются «по северной кромке приуральской степи и занимают территорию среднего течения р. Белой» [Сунгатов, 1998. С. 5; Сунгатов, 2002. С. 25].
Несмотря на многолетнюю историю изучения турбаслинской культуры, целый ряд вопросов, связанных с ней, до сих пор остается до конца не решенным. В первую очередь, это касается генезиса культуры, этнической принадлежности ее носителей, характера взаимодействия «турбаслинцев» с другими этнокультурными общностями и, наконец, причисления тех или иных погребений к собственно турбаслинским [Мажитов, 1968. 
С. 69-70; Матвеева, 1971. С. 129-132; Матвеева, 2004. С. 10-11, 62-64; Васюткин, 1971. С. 137-138; Генинг, 1987; Иванов, 1984. С. 30-36; Иванов, 2017. С.11-17; Сунгатов, 1998. С.5-16; Казаков,
1998. С.97-99; Казаков, 2011. С. 17; и др.]. Не сложилось в научной литературе единого мнения и о хронологических рамках турбаслинской культуры (табл. 1).

Таблий 1

Хронологические рамки турбаслинской культуры в работах разных исследователей Table 1

Chronological frameworks of the Turbasly culture in the studies of different scholars

\begin{tabular}{|c|c|c|c|c|}
\hline Исследователи & Год & Название & Хронологические рамки & Ссылка \\
\hline Н.А.Мажитов & 1968 & Турбаслинская культура & V-VII вв. & Мажитов, 1968. С. 68 \\
\hline Г.И. Матвеева & 1971 & Турбаслинская культура & VI-IX вв. & Матвеева, 1971. С. 132 \\
\hline С.М.Васюткин & 1971 & Турбаслинская культура & V-VIII вв. & Васюткин, 1971. С. 138 \\
\hline Н.А. Мажитов & $\begin{array}{l}1977, \\
1981\end{array}$ & Турбаслинская культура & VII-VIII вв. & $\begin{array}{l}\text { Мажитов, 1977. С. } 93 \\
\text { Мажитов, 1981. С. } 23\end{array}$ \\
\hline В.А.Иванов & 1984 & Турбаслинская культура & $\begin{array}{c}\text { начало VI - середина VII } \\
\text { вв. }\end{array}$ & Иванов, 1984. С. 32 \\
\hline В.Ф.Генинг & 1987 & $\begin{array}{c}\text { Турбаслинский } \\
\text { археолого-этнический } \\
\text { тип } \\
\end{array}$ & V-VII вв. & Генинг, 1987. С.99 \\
\hline Ф.А.Сунгатов & 1998 & Турбаслинская культура & конец V - начало VIII вв. & Сунгатов, 1998. С. 113 \\
\hline Г.И. Матвеева & 2004 & Турбаслинская культура & конец IV - VII вв. & Матвеева, 2004. С. 163 \\
\hline Е.П.Казаков & 2011 & $\begin{array}{c}\text { Турбаслинско- } \\
\text { именьковская общность }\end{array}$ & вторая пол. VI - VII вв. & Казаков, 2011. С. 18-21 \\
\hline Ф.А.Сунгатов & 2020 & Турбаслинская культура & V-VIII вв. & Сунгатов, 2020. С. 73 \\
\hline
\end{tabular}

В данной статье рассмотрен ряд погребений, материалы которых имеют опорное значение для хронологии древностей Южного Приуралья эпохи Великого переселения народов и раннего средневековья.

\section{Часть І. О нижней хронологической} границе турбаслинской культуры

Нижнюю границу турбаслинской культуры Ф.А. Сунгатов определяет концом V в. н.э. [Сунгатов, 1998. С. 114; Сунгатов, 2002. С.26]. По мнению исследователя, после $370-$ хгг. потомки позднесарматских племен с правобережья р. Белая приняли участие в походах гуннов на запад [Сунгатов, 1998. С. 105-107]. Как отмечает исследователь, в состав гуннского союза входили и «племена джетыасарской культуры Восточного Приаралья» [Сунгатов, 2002. С. 26]. В результате военных неудач и распада гуннской конфедерации смешанное гунно-сармато-джетыасарское население продвинулось на территорию Приуралья [Сунгатов, 1998. C. 114; Сунгатов, 2002. С. 26].

К одним из ранних турбаслинских комплексов Ф.А.Сунгатовым отнесен кург. 18/1 Дежневского могильника [Сунгатов, 1998. С. 85], материалы которого представлены пряжкой со вставками из красного стекла в перегородчатых выемках, расположенных на внешней накладке обоймы (рис. 1, 2), костяным наконечником стрелы (рис. 1,1$)$ и двумя глиняными плоскодонными сосудами (рис. 1,3 , 4) [Пшеничнюк, 1968. С. 109; Красноперов, 2012. С.223] «низких и средних пропорций» [Сунгатов, 1998. C. 85].

А.Х.Пшеничнюком плоскодонные сосуды из Дежневских курганов были соотнесены с керамикой т.н. «романовского» типа [Пшеничнюк, 1968. С. 111]. В свою очередь, Н.А. Мажитовым данные сосуды выделены в типы 8 и 9 турбаслинской керамической группы [Мажитов, 1977. С.47-48;
C. 204. Табл. V, 11; С. 205. Табл. VI, 8]. Г.И. Матвеева, рассматривая в целом Дежневский могильник в качестве раннего памятника турбаслинской культуры, интерпретировала находки плоскодонной керамики в его комплексах как показатель тесных связей между «именьковцами» и «турбаслинцами» [Матвеева, 2004. С. 63, 156. Рис. 33, 11, 12]. По мнению Ф.А.Сунгатова, сосуды с плоским дном низких и средних пропорций имеют наибольшее сходство с керамикой из памятников позднесарматского времени [Сунгатов, 1998. С.39-40], а близость турбаслинской плоскодонной посуды с именьковскими («романовскими») образцами может быть объяснена соседством предков носителей указанных керамических традиций «в период их пребывания в сер. I тыс. в Восточном Приаралье» [Сунгатов, 2002. С. 27].

Датировка кург. 18/1 Дежневского могильника также является неоднозначной. Пряжка с перегородчатой инкрустацией на щитке имеет близкие аналогии на территории Нижнего и Среднего Прикамья, а также Пермского Приуралья [Генинг, 1976. С. 105. Рис. 32, 6; Красноперов, 2012. С. 242. Рис. 10, 10; Перескоков, 2018. С.67, 256, 257. Рис. 40, 16; 41, 9].

А.В.Богачевым «дежневская» пряжка была отнесена к «тураевскому» этапу (V - первая пол. VIв.) эволюции поясных наборов Среднего Поволжья [Богачев, 1992. С.152, 183. Прил. 1]. С точки зрения Ф.А. Сунгатова, подобные изделия характерны для керченских комплексов IV-Vвв., а на территории Южного Приуралья они начинают фиксироваться в конце V в. [Сунгатов, 1998. C. 66,85$]$.

По мнению М.М.Казанского, появление пряжек рассматриваемого типа связано с распространением сасанидских традиций в результате миграции «в течение Vв. каких-то групп кочевников из 


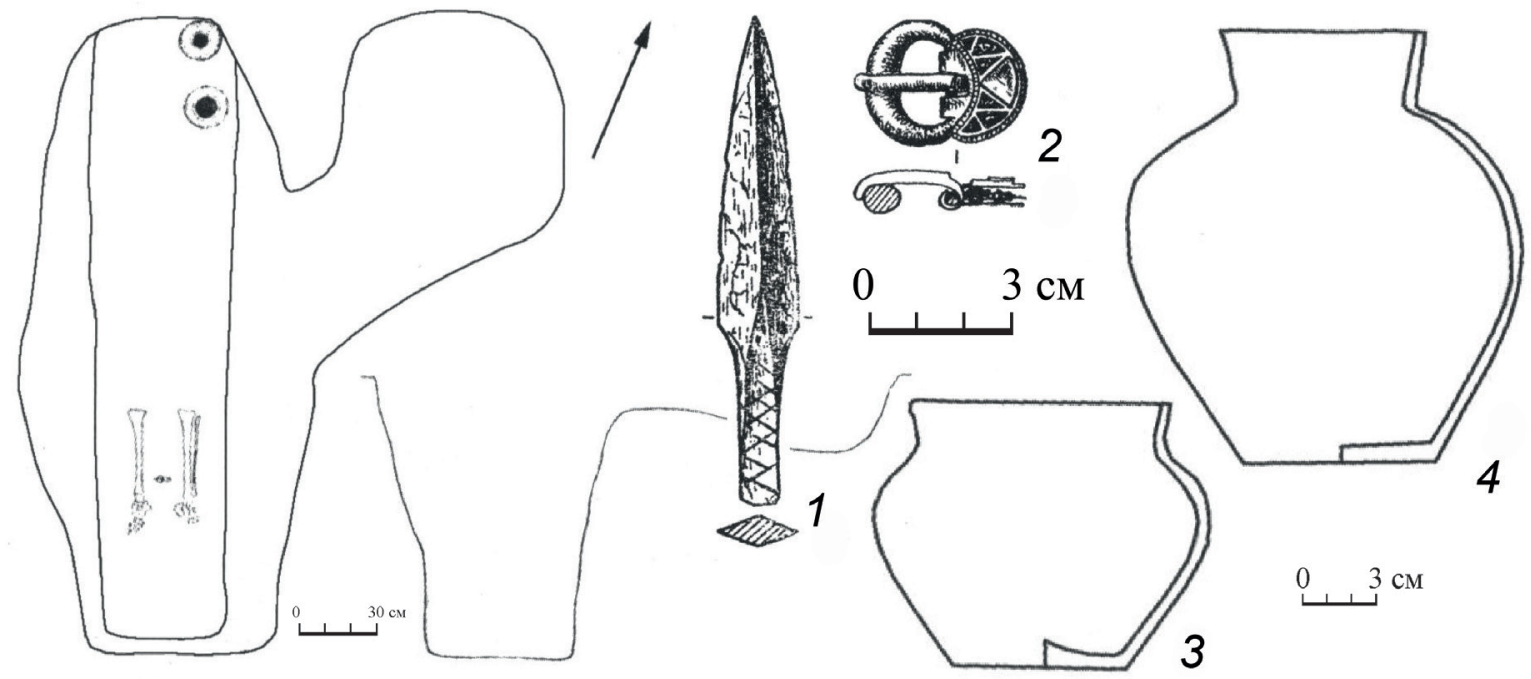

Рис. 1. Дежневский могильник, кург. 18, п. 1 (по: [Красноперов, 2012. С. 243. Рис. 11-А])

Fig. 1. Dezhnevsky necropolis, barrow 18, burial 1 (after: [Krasnoperov, 2012. p. 243. Fig. 11-A])

Центральной Азии», пряжка же из Дежневского могильника датирована исследователем гуннским временем (конец IV - первой пол. Vв.) [Казанский, 2002. С. 193-197. Рис. 1, 8].

Как отмечает А.А.Красноперов, «дежневский» экземпляр и его аналоги следует относить к самостоятельному прикамскому варианту серии «Цибилиум-Тураево», выделяемой в рамках группы «догуннских» полихромных изделий (по С.И.Безуглову). Подобные ременные гарнитуры имеют прототипы в комплексах «второй группы финального («катакомбного») этапа культуры кочевников Нижнего Подонья позднесарматского времени», а истоки данного полихромного стиля связаны с культурами Закавказья. По мнению исследователя, появление в Прикамье данных пряжек не ранее середины IV в. (наиболее вероятно - третьей четверти IV в.) связано с возвращением представителей местных племен - «ветеранов воинского отряда», - принимавших участие в военных действиях в «далеких странах» [Красноперов, 2012. C. 218-222].

Таким образом, если вслед за Ф.А.Сунгатовым причислять кург. 18/1 Дежневского могильника к комплексам турбаслинской культуры, то новейшие датировки пряжки с перегородчатой инкрустацией на щитке никак не согласуются с концепцией исследователя о появлении в Приуралье новых групп населения лишь в конце $\mathrm{V}$ в. В то же время, мы склонны считать, что круг вопросов, связанных с находками плоскодонной керамики на территории турбаслинских некрополей (в т.ч. и поздних - см. Часть II), не может быть решен на данный момент однозначно и требует дополнительного рассмотрения в рамках специализированной работы.

\section{Часть II. О верхней хронологической}

\section{границе турбаслинской культуры}

«В конце VIв.» [Сунгатов, 2002. С.26] либо «на этапе VII-VIIIвв.» [Сунгатов, 2020. С. 79] Ф.А.Сунгатовым допускается возможность продвижения в среднее течение р. Белая новой волны носителей джетыасарской культуры, родственной «турбаслинцам» «по культуре и языку» [Сунгатов, 2002. С. 27]. С появлением кушнаренковских племен часть турбаслинского населения могла быть вытеснена на запад, в Поволжье, а «остальные были подчинены новым пришельцам» и продолжили жить в Приуралье до VIIIв. включительно [Сунгатов, 1998. С. 114-115; Сунгатов, 2002. С. 29].

К поздним турбаслинским памятникам VIIVIII вв. Н.А. Мажитовым и Ф.А. Сунгатовым отнесены Ново-Турбаслинский и Шареевский могильники [Мажитов, 1981. С.23-24; Сунгатов, 1998. С.111], а также один из курганов (рис. 2, A1-12) могильника «Чайка-1» [К проблеме..., 2018. С. 158; Сунгатов, Куфтерин, 2020. С. 106].

Этим же временем датирован ряд наиболее богатых (турбаслинских - по Н.А.Мажитову и Ф.А.Сунгатову) для Южного Приуралья комплексов: Новиковское погребение (рис. 2, Б1-18) [Археологическая..., 1976. С. 125-126; Сунгатов, 1998. С. 68,70 . Рис. 10,$4 ; 11,25$; и др.], некоторые захоронения Кушнаренковского могильника (рис. 3, A1-21; 3, Б1-15) [Мажитов, 1977. С. 191. Табл.I; Сунгатов, 1998. С. 84, 86-87. Рис. 15] и женское погребение во дворе БГМУ (рис. 4, A118) [Сунгатов, 1998. С. 106; Сунгатов, 2020. С. 78].

Описание особенностей погребального обряда и инвентаря из перечисленных археологических памятников приведено во многих исследованиях [Булычев, 1902. С.9-10; Мажитов, 1959. С. 111-142; Матвеева, 1968; Смирнов, 1957. С. 5861; Ахмеров, 1970. С.162-164; Генинг, 1977; К проблеме..., 2018. С. 149-150, 155-158; Сунгатов, Куфтерин, 2020; и др.], что позволяет сосредоточить внимание непосредственно на анализе вещей-хроноиндикаторов и определении датировки интересующих нас комплексов.

Так, золотые и серебряные цепи «сложного» плетения, аналогичные экземпляру из Новиковки (рис. 2, Б18), зафиксированы в Крыму, Придонье, Поволжье и Прикамье [Голдина, 2012. С.114. Рис. 4; Сунгатов, 2020. С. 78]. По мнению Р.Д. Голдиной, данные изделия были изготовлены одной партией в «мастерских византийского круга на ру- 

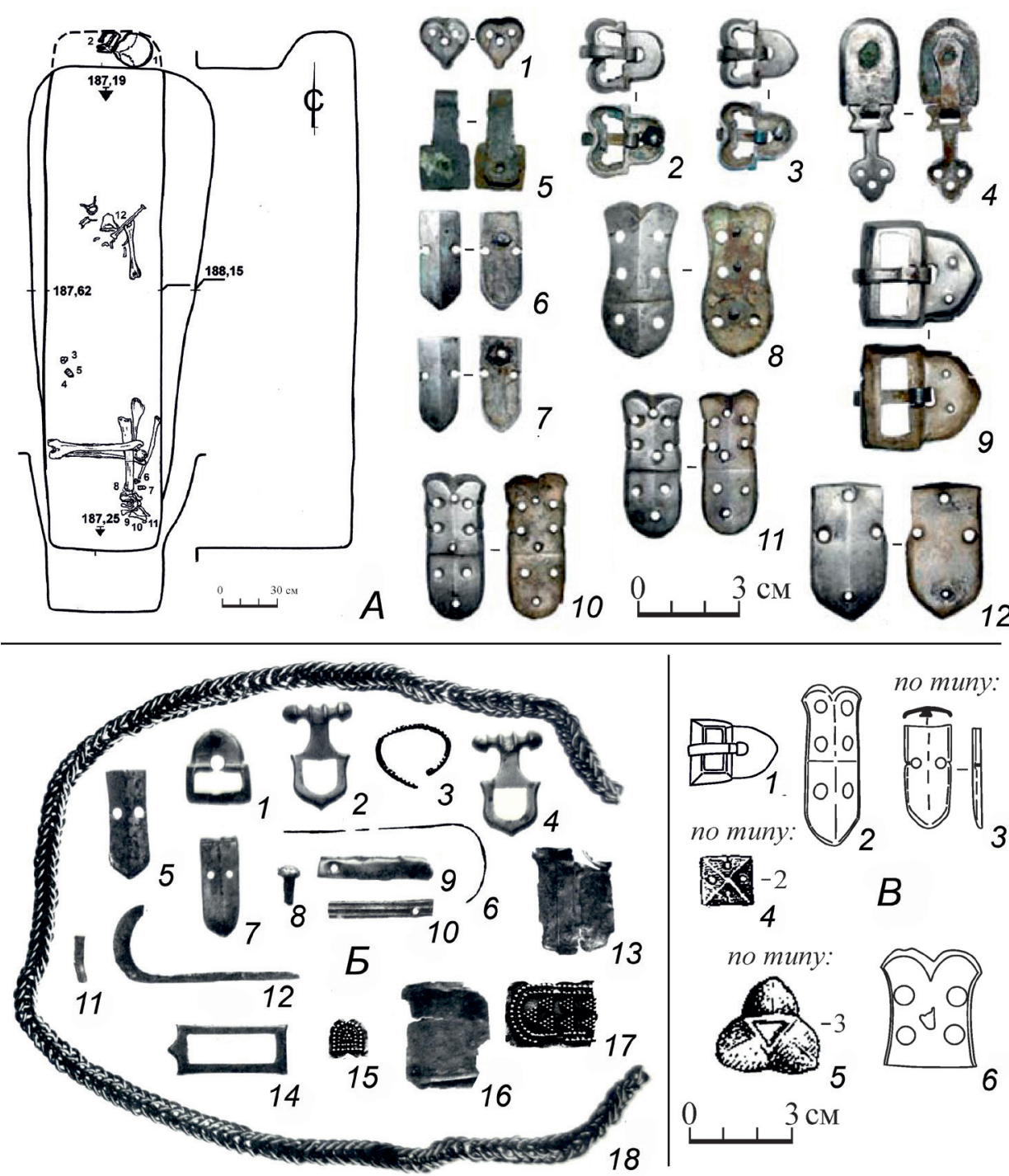

Рис. 2. Погребения с «геральдической» ременной гарнитурой.

$A$ - Могильник «Чайка-1», кург. 7 (по: [Сунгатов, 2020. С. 75. Рис. 2; Сунгатов, Куфтерин, 2020. С. 98. Рис. 2]) $Б$ - Новиковское погребение (по: [Булычев, 1902. Табл. II])

$B$ - Ново-Турбаслинский могильник, кург. 13, п. 2. 1, 2, 6- ОФ 17046, НМ РБ'; 3 - рисунок И.О.Гавритухина; 4, 5 - (по: [Мажитов, 1977. С. 191. Табл. I, 47, 54])

Fig. 2. Burials with 'heraldic' belt fittings.

$A$ - "Chaika-1" necropolis, barrow 7 (after: [Sungatov, 2020. p. 75. Fig. 2; Sungatov, Kufterin, 2020. p.98. Fig. 2]) $B$ - Novikovka burial (after: [Bulychev, 1902. Table II])

$C$ - Novo-Turbasly necropolis, barrow 13, burial 2. 1, 2, 6-OF 17046, NM RB; 3 - drawing by I. Gavrituhin; 4, 5 - (after: [Mazhitov, 1977. p. 191. Table I, 47, 54])

беже VI - VII вв.», а в Приуралье и Верхнем Прикамье, судя по всему, они распространились уже в VIIв. по речным торговым путям [Голдина, 2012. C.113]. В Башкирии еще одна плетеная цепь выявлена при земляных работах в Уфе на Проспекте Октября [Голдина, 2012. С.111], также фрагмент подобного украшения обнаружен в п. 419 Бирского могильника [Мажитов, 1986] совместно с «геральдическими» накладками, бляшками и наконечниками второй половины VIIв. [Гавритухин, 2001. С. 39-40, 83, 84. Рис. 15, 16].

Рамчатой накладке с фигурным краем (рис. 2, Б14) типа (Ковалевская-13a) [Ковалевская, 2000. C. 154, 338. Табл. 5] выявлены аналогии среди Никольских находок [Булычев, 1904. С.11. Табл. III, 21; Белявская, 2019б. С.152. Рис.2, 9]. Судя по всему, более ранний образец данного типа, отнесенный исследователями к первой половине VIIв., обнаружен в Верх-Саинском могильнике, а датировка «новиковского» экземпляра может быть определена не позднее середины VII в. [Гавритухин, Обломский, 1996. С.273. Рис. 89, 97, 122; Гавритухин, 2001. С. 37-40, 78. Рис. 10, 8; Голдина и др., 2018. С. 587. Табл. 431, 26$].$

Квадратные, пирамидальные в сечении, накладки (рис. 2, B4) типа (Ковалевская-4-1) [Ковалевская, 2000. С.147], бытование которых ограничено исследователями первой половиной VIIв. [Голдина и др., 2018. С.588. Табл. 432, 44], имеют аналогии на территории Крыма [Ковалевская, 2000. С. 147] и Пермского Приуралья [Голдина и др., 2018. С. 160. Табл. 4, 5, 6]. В Ново-Турбаслин-

\footnotetext{
${ }^{1}$ Коллекция Ново-Турбаслинских курганов. Раскопки Н.А. Мажитова, 1957 г., 1958 г., ОФ 17046 / НМ РБ
} 

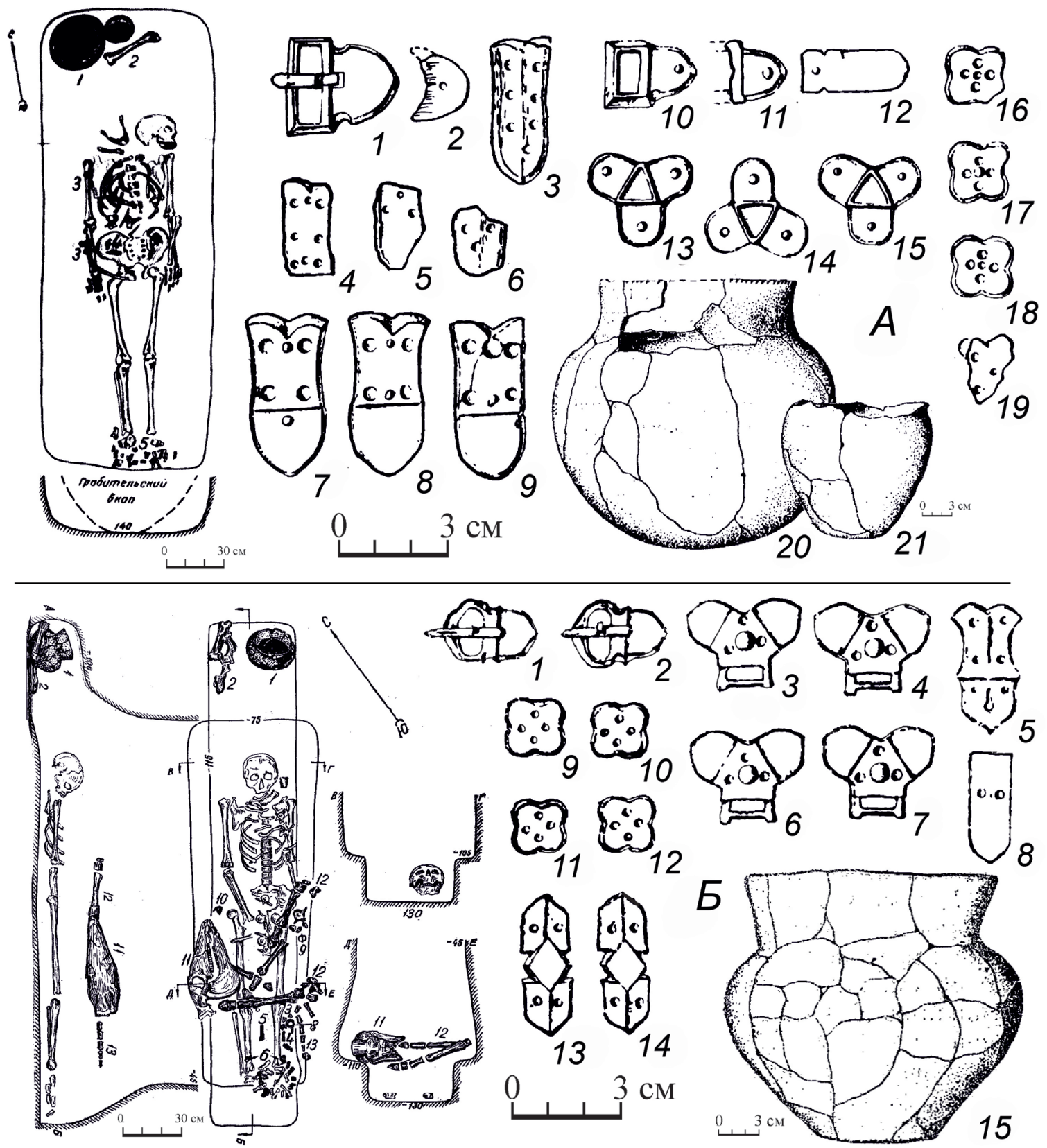

Рис. 3. Погребения с «геральдической» ременной гарнитурой

$A$ - Кушнаренковский могильник, п. 17 (по: [Акимова, Генинг, 1960. Рис. 14; Генинг, 1977. С. 100. Рис. 7, 8-28]) $Б$ - Кушнаренковский могильник, п. 2 (по: [Генинг, 1977. С. 93. Рис. 3, 1-14, 23; С. 95. Рис. 4])

Fig. 3. Burials with 'heraldic' belt fittings.

$A$ - Kushnarenkovo necropolis, burial 17 (after: [Akimova, Gening, 1960. Fig. 14; Gening, 1977. p. 100. Fig. 7, 8-28]) 5 - Kushnarenkovo necropolis, burial 2 (after: [Gening, 1977. p. 93. Fig. 3, 1-14, 23; p. 95. Fig. 4])

ском могильнике данный тип зафиксирован также в курганах 13/1, 18/1 и 18/4 [Мажитов, 1959. C. 128,133$]$.

«Рогатые» одночастные накладки (рис. 2, $B 6)$ со слабо отогнутыми углами и прорезной орнаментацией в виде симметричных кругов (по И.О. Гавритухину) [Гавритухин, Обломский, 1996. С. 89] имели распространение на территории Поволжья [Казаков, 1998. С. 115. Рис. 3, 2], Прикамья [Гавритухин, 2001. С. 80. Рис. 12, 4], Центральной Азии [Торгоев, 2005. С. 89. Рис. 1, 10], Приаралья [Левина, 1996. С.325. Рис. 130, 28, 33, 34], Крыма [Айбабин, 1999. С.318. Табл. XXXI, 42, 44] и др. В Башкирии аналогичные накладки зафиксированы на Кушнаренковском селище [Генинг, 1977.
С. 129. Рис. 18,2$]$ и среди депаспортизированных материалов Бахмутинского могильника [Гавритухин, 2001. С. 76. Рис. 8, 14]. Согласно наблюдениям И.О.Гавритухина, данный тип встречается в комплексах конца VI - первой половины VII вв. [Гавритухин, 2001. С. 56-66]. А.И.Айбабиным подобные украшения датированы первой половиной VIIв. [Айбабин, 1999. С. 276]. По мнению А.И. Торгоева, они бытуют на протяжении всего VIIв. в Крыму, Башкирии и Приаралье [Торгоев, 2005. C. 88-89].

Наконечники (рис. 2, A6-7, $55,57, B 3 ; 3,58$ ) с прямыми параллельными боками - (по И.О. Гавритухину) [Гавритухин, Обломский, 1996. С. 85] имели распространение на территории Пермского 
Приуралья [Голдина и др., 2018. С. 180. Табл. 24, 5], Поднепровья [Скіба, 2016. С. 203. Рис. 74, 8-10], Причерноморья [Айбабин, 1990. С.227. Рис.48, 7], Приаралья [Левина, 1996. С. 326. Рис. 131, 13, $14,24]$ и Центральной Азии [Торгоев, 2005. С. 89. Рис. 1,7$]$, близкие аналогии им зафиксированы на Алтае [Гаврилова, 1965. Табл. XVIII, 15]. В Башкирии подобные изделия обнаружены также в Сынтыш-Тамакском могильнике [Васюткин, 1967. С. 30-34], оставленном носителями кушнаренковской культуры. Согласно разработанной А.В.Богачевым периодизации средневолжских поясных гарнитур, данный тип наконечников характерен для «зиновьевского» этапа (вторая половина VI - VIIв.) [Богачев, 1992. С. 154. Рис. 28]. И.О. Гавритухиным указанные изделия отнесены к первой половине VII в. [Гавритухин, 2001. С. 38-40, 78. Рис. 10, 10], аналогичной датировки придерживаются ижевские исследователи [Голдина и др., 2018. С. 588. Табл. 432, 40].

Двухчастные накладки (рис. 2, A10-11, B2; 3, A3) с несильно профилированными «рогами», с прорезной орнаментацией в виде симметричных кругов и вытянутым нижним щитком (по И.О. Гавритухину) [Гавритухин, Обломский, 1996. С.90] имеют соответствия в Верх-Саинском могильнике [Голдина и др., 2018. С.440. Табл. 284, 16], близкие по морфологии изделия выявлены в склепах у г. Керчь и с.Скалистое [Айбабин, 1990. С.229. Рис. 50, 45]. В Башкирии данный тип обнаружен, кроме того, в Сынтыш-Тамакском могильнике [Васюткин, 1967. С.30-34]. А.В.Богачевым подобные накладки датированы второй половиной VI - VII вв. [Богачев, 1992. С. 154. Рис. 28], в Крыму они встречены в комплексах VIIв. [Айбабин, 1990. C. 52].

Четырехлепестковые накладки (рис. 3, Al618, Б9-12) типа (Ковалевская-33-1) [Ковалевская, 2000. С. 158] имеют аналогии на территории Центральной Азии [Ковалевская, 2000. С. 167. Рис. XVI, 14], Поволжья [Казаков, 2011. С.25, 32. Рис.3, 2; 10, 7, 8, 10, 11 и др.; Гавритухин, 2001. С. 73. Рис. 5,10$]$, Пермского Приуралья [Голдина и др., 2018. С. 163. Табл. 7, 2], Приаралья [Левина, 1996. С. 327. Рис. $132,16,18,22,23]$ и др. Е.П. Казаковым накладки данного типа были отнесены к т.н. «раннегеральдическому» («коминтерновскому») горизонту и датированы третьей четвертью VІв. [Казаков, 1998. С. 107]. Как отмечает И.О. Гавритухин, в Прикамье четырехлепестковые накладки появляются не раньше середины VIв., а, в целом же, наибольшее их распространение приходится на конец VI - первую половину VII вв. [Гавритухин, Иванов, 1999. С.107-108]. По мнению Р.Д.Голдиной и ее соавторов, в Верх-Саинском могильнике рассматриваемые изделия характерны для погребений первой половины VII в. [Голдина и др., 2018. С. 588. Табл. 432, 36].

Металлическая обувная гарнитура из женского погребения во дворе БГМУ рассмотрена нами ранее в отдельной статье [Белявская, 2019а]. Хронологические позиций парных деталей - пря- моугольнорамчатых пряжек 7-го варианта (по А.И. Айбабину) (рис. 4, A1; а также: 3, A10-11), трехщитковых накладок (рис. $4, A 3)$ и горизонтальносимметричных (по И.О. Гавритухину) или двухщитковых (по А.И.Айбабину) накладок (рис. 4, $A 2)$ - по многочисленным аналогиям с территорий Причерноморья, Северного Кавказа и Поднепровья были определены от второй половины VI до середины VIIв. [Айбабин, 1990. С. 49, 54-55, 64, 225; Гавритухин, Обломский, 1996. С. 218. Рис. 40, 27, 28; Хайрединова, 2003. С. 129, 130, 141. Рис. 2 , 8; 1, 22, 28; Gavritukhin, 2018, P. 62-63, 87-89, 279. Fig. 96, 27], а вероятное время возникновения самого комплекса ограничено концом VI - серединой VII вв. [Белявская, 2019а. С. 134].

Не противоречит, на наш взгляд, указанным датировкам и находка наконечника ремня (рис. 4 , A14), имеющего близкие соответствия в Приазовье [Атавин, 1996. С. 239. Табл.2], Крыму [Айбабин, 1990. С. 231. Рис. 52, 19], Поволжье, Поднепровье [Скіба, 2016.С.215. Рис. 86, 14] и Предкавказье [Gavritukhin, 2018. P.316. Fig. 133, 49, 50].

Список соответствий можно продолжать и дальше. Более же подробно вопросы типологии и периодизации ременных гарнитур с территории Поволжья и Приуралья рассмотрены в целой серии работ [Генинг, 1979. С. 100-101; Богачев, 1992; Ковалевская, 2000; Голдина и др., 2018; и т.д.]. Отдельно отметим изыскания И.О.Гавритухина, ряд положений которых составили основу нашего исследования [Гавритухин, Обломский, 1996. С. 84-89; Гавритухин, Иванов, 1999; Гавритухин, $2001 ;$ и др.].

Сосуды из Кушнаренковского могильника отнесены В.Ф.Генингом к «романовскому» IIму (рис. 3, Б15), турбаслинскому (рис. $3, A 21)$ и «бирскому» (рис. 3, A20) типам - по разработанной им классификации [Генинг, 1977. С. 112-113]. Н.А. Мажитовым и Ф.А.Сунгатовым рассматриваемые экземпляры причислены к турбаслинскому керамическому комплексу: типы 9, 10 и 11 - по Н.А. Мажитову [Мажитов, 1977. С.206, 207. Табл. VII, 2, 18; VIII, 15]; круглодонные сосуды средней высоты, низкие и высокие плоскодонные сосуды - по Ф.А. Сунгатову [Сунгатов, 1998, С. 26, 28, 29. Рис. 2, 43, 83, 114].

Е.П.Казаковым Кушнаренковский могильник, совместно с Коминтерновским II, Уфимским, VМаклашеевским, IX Измерским, Ташкирменьским и Старомайнским, рассматриваются в качестве некрополей с биритуальным обрядом т.н. «турбаслинско-именьковской общности» [Казаков, 2011. С. 17]. Как отмечает Г.И. Матвеева, Кушнаренковский могильник является «синкретичным памятником», в котором наряду с «двумя типично именьковскими трупосожжениями обнаружены погребения, совершенные по турбаслинскому и кушнаренковскому обряду». Именно с влиянием носителей кушнаренковской культуры, по мнению исследователя, следует связывать обнаруженный в п. 2 (рис. 3, Б) жертвенный комплекс из челюсти и конечностей лошади [Матвеева, 2004. С. 32-33]. 

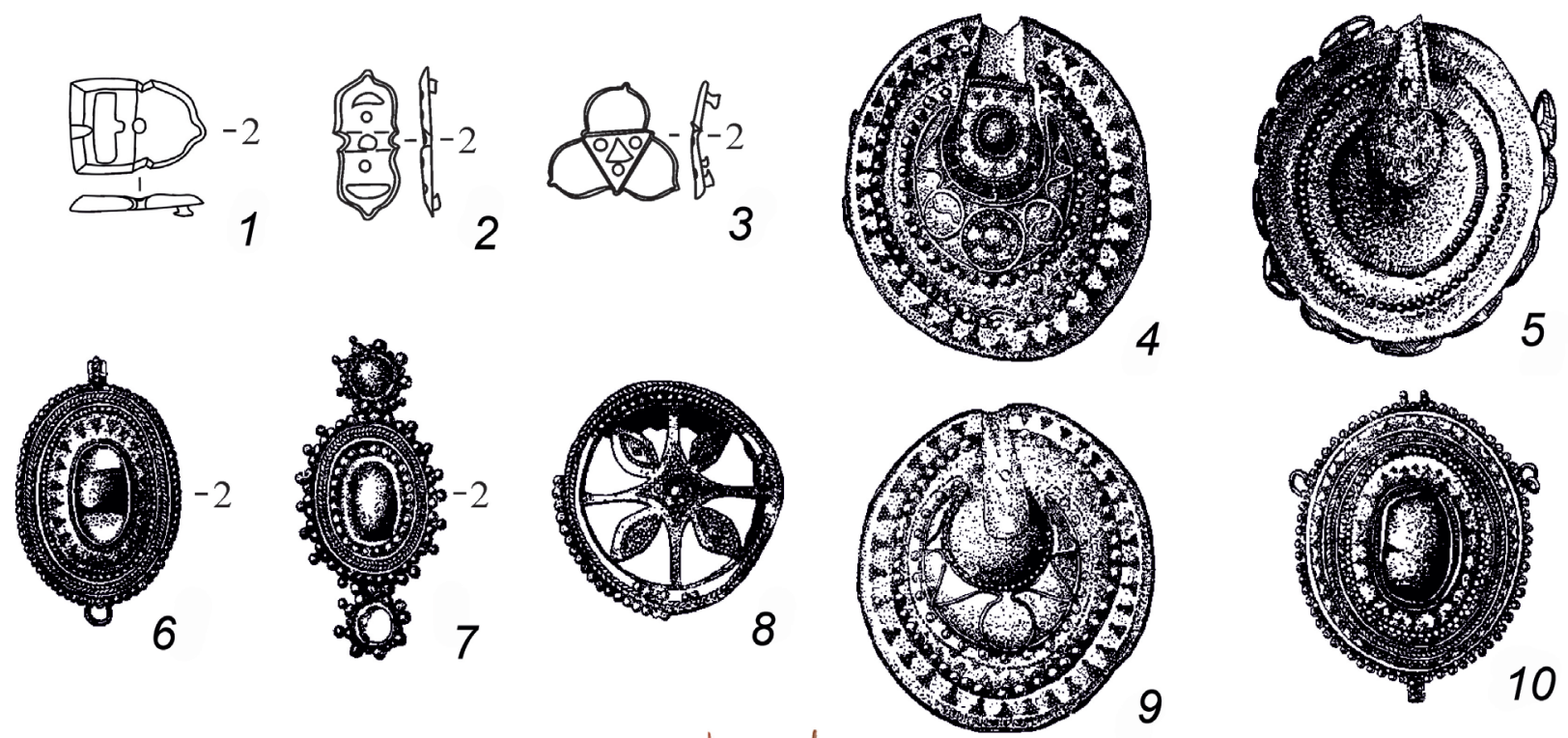

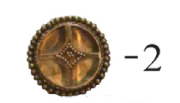

11

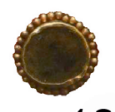

12
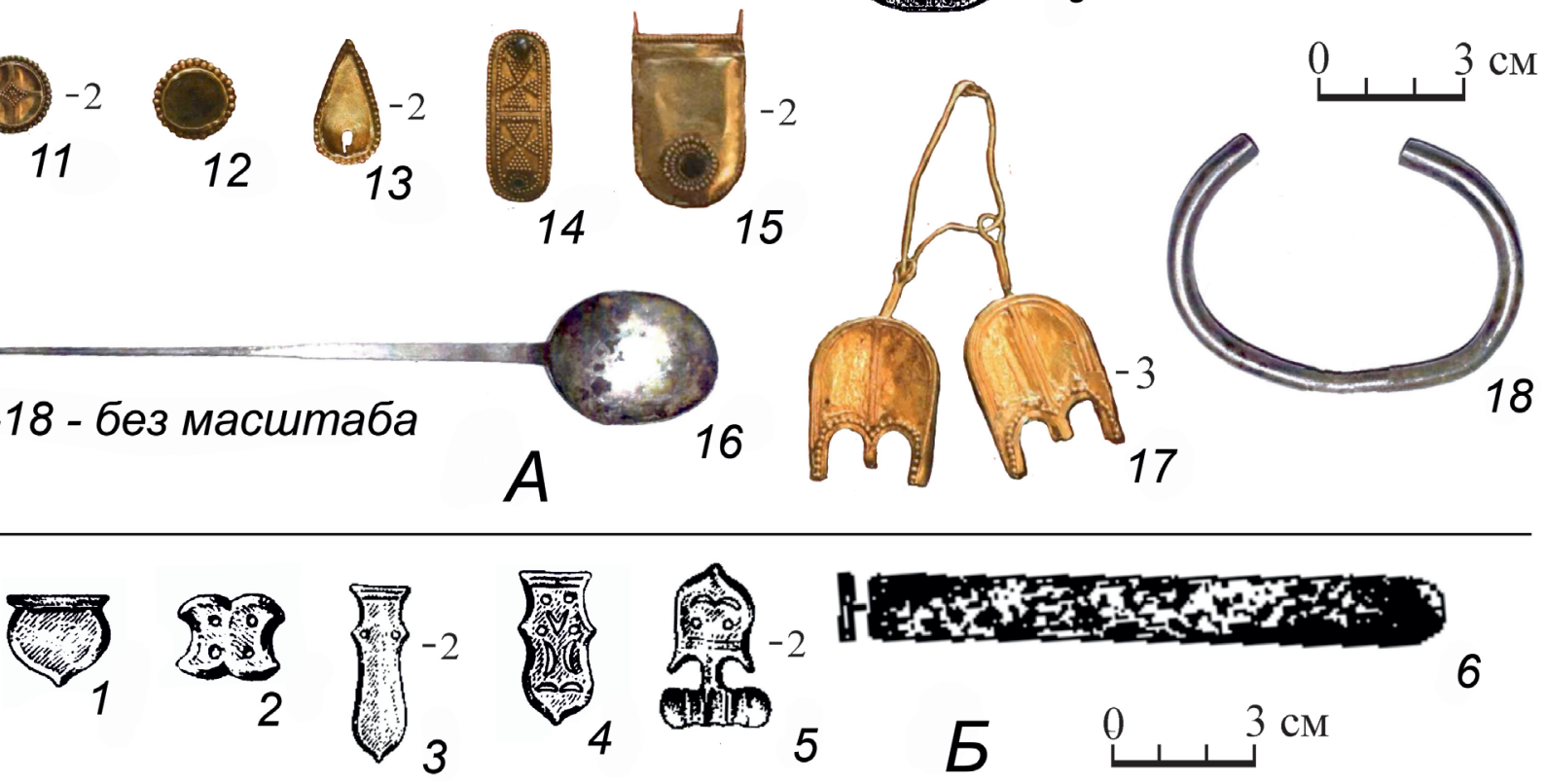

Рис. 4. Погребения с «геральдической» ременной гарнитурой.

$A$ - женское погребение во дворе БГМУ. 1-3 - (по: [Белявская, 2019а. С. 134. Рис. 1]; 4-10 - (по: [Смирнов, 1957. С.59. Табл. IX]); 11-15, 17 - (по: [Мажитов и др., 2008. С. 55, 62-63]); 16, 18 - (по: [К проблеме..., 2018. С. 320. Рис. 163, 5, 6]) Б - Ново-Турбаслинский могильник, кург. 27, п. 8. 1-5 - (по: [Мажитов, 1977. С. 191. Табл. I, 55-59]; 6 - (по: [Сунгатов, 1998. С. 68 . Рис. 10, 13])

Fig. 4. Burials with 'heraldic' belt fittings.

$A$-female grave on the territory of the courtyard of the BGMU. 1-3-(after: [Belyavskaya, 2019a. p. 134. Fig. 1]; 4-10-(after: [Smirnov, 1957.p. 59.Table IX]); 11-15, 17-(after:[Mazhitov etal., 2008.p. 55, 62-63]); 16, 18-(after:[On the problem...,2018.p. 320.Fig. 163, 5, 6]) $B$ - Novo-Turbasly necropolis, barrow 27, burial 8. 1-5 - (after: [Mazhitov, 1977. p. 191. Table I, 55-59]; 6 - (after: [Sungatov, 1998. p. 68. Fig. 10, 13])

К кушнаренковской культуре В.В. Овсянниковым отнесены погребения во дворе БГМУ и Новиковское захоронение [Овсянников, 1995. С. 138139], вещевой инвентарь которых (поясной набор, золотая цепь, вооружение) имеет аналогии в Сынтыш-Тамакском и Такталачукском могильниках [Васюткин, 1967. С. 30-34; Казаков, 1981. С. 137].

Если же допустить, что все комплексы, рассмотренные во второй части статьи, оставлены «турбаслинцами», то мы придем к выводу, что наиболее богатые захоронения турбаслинской культуры (наряду с курганами 13/1, 18/1, 18/4 Ново-
Турбаслинского и п. 21, п. 28 Кушнаренковского могильников) имели распространение не в «VIIVIII вв.», а в конце VI - середине VII вв.

Позднейшим погребением в Ново-Турбаслинском могильнике, на наш взгляд, является кург. 27/8 [Гавритухин, Обломский, 1996. С.273. Рис. 89, 35-41]. Ременная гарнитура «геральдического» облика (рис. 4, Б1-б) из указанного захоронения может быть датирована серединой - второй половиной VIIв. [Амброз, 1973. С.288. Рис. 1, 78; Голдина и др., 2018. С. 589. Табл. 433, 56; и др.]. 
Материалы Шареевского могильника, в котором помимо турбаслинских сосудов, зафиксирована и керамика «кушнаренковского» типа [Матвеева, 1968. С.20; Генинг, 1987. С.86; Султанова, 2000. С. 128], являются «достаточно невыразительными» [Сунгатов, 1998. С. 111]. Датировка ременных принадлежностей из п. 8,9 и 13 [Матвеева, 1968. С. 13-19. Рис. 18, 24, 33] едва ли выходит за рамки VII в. [Голдина, Водолаго, 1990. C. 164. Табл. LXVII, 13; Гавритухин, 2001. С.61, 80. Рис. 12 , 6]. Более же предметно говорить о хронологических рамках Шареевского могильника станет возможно, на наш взгляд, лишь после его полной перепубликации.

\section{Заключение}

Турбаслинская культура как «культура в чистом виде», судя по всему, начинает угасать уже с середины VII века. Во второй половине VIIв. продолжается процесс смешения «турбаслинцев» с бахмутинским и кушнаренковским населением, отраженный в изменении вещевого инвентаря, погребального обряда и керамики поздних погребений Бирского могильника [Султанова, 2000. C. 126-128]. В конце VII либо на рубеже VIIVIIIвв. турбаслинская культура в Приуралье, по нашему мнению, окончательно прекращает свое существование.

\section{СПИСОК ЛИТЕРАТУРЫ}

Айбабин А.И. Хронология могильников Крыма позднеримского и раннесредневекового времени // Материалы по археологии, истории и этнографии Таврии. Вып. 1 / Ред.-сост. А.И. Айбабин. Симферополь: Таврия, 1990. С. 3-86, 174-241.

Айбабин А.И. Этническая история ранневизантийского Крыма. Симферополь: Дар, 1999. 352 с.

Акимова М.С., Генинг В.Ф. Отчет об исследованиях археологических памятников у с.Кушнаренкова Башкирской АССР в 1959 году. М., 1960 // Архив ИА РАН. Р-1. № 1953.

Амброз А.К. (Рец. на:) Erdélyi I., Ojtozi Е., Gening W. Das Gräberfeld von Nevolino. Budapest: Akadémiae Kiadó, 1969. 93 c., 26 рис. в тексте, 101 табл., 1 карта, 2 плана // Советская археология. № 2. 1973. C. 288-298.

Археологическая карта Башкирии / Отв. ред. О.Н.Бадер. М.: Наука, 1976. 264 с.

Атавин А.Г. Погребения VII - начала VIIIвв. из Восточного Приазовья // Культуры Евразийских степей второй половины I тысячелетия н.э. / Отв. ред. Д.А.Сташенков. Самара: СОИКМ, 1996. С. 208-264.

Ахмеров Р.Б. Уфимские погребения IVVIIвв. н.э. и их место в древней истории Башкирии // Древности Башкирии / Отв. ред. А.П. Смирнов. М.: Наука, 1970. С. 161-163.

Белявская О.С. К изучению элитного раннесредневекового погребения на территории Уфы // Новые материалы и методы археологического исследования: От критики источника к обобщению и интерпретации данных. Материалы V Междунар. конф. молодых ученых. М.: ИА РАН, 2019a. C. 133-135.

Белявская О.С. «Никольские находки» IIIVIIвв. в лесостепном Предуралье // Вестник Московского университета. Сер. 8. История. №4. 2019б. С. 144-159.

Богачев А.В. Процедурно-методические аспекты археологического датирования (на материалах поясных наборов IV-VIII вв. Среднего Поволжья). Самара: Артефакт, 1992. 208 с.

БулычевН.И. Древности из Восточной России. Вып.І. М.: Товарищество типографии А.И.Мамонтова, $1902.30 \mathrm{c}$.

Булычев Н.И. Древности из Восточной России.
Вып. II. СПб.: Товарищество художественной печати, 1904. $15 \mathrm{c}$.

Васюткин С.М. Отчет об археологических исследованиях в Башкирской АССР в 1966г. Уфа, 1967 // Архив ИА РАН. Р-1. № 3242.

Васюткин С.М. О периодизации этнической истории населения Башкирии эпохи средневековья (III-XIII вв.) // Археология и этнография Башкирии. T.IV / Отв. ред. Ю.В. Бромлей, Р.Г. Кузеев. Уфа: БФАН СССР, 1971. С. 135-139.

Гаврилова А.А. Могильник Кудыргэ как источник по истории алтайских племён. М.-Л.: Наука, 1965. $144 \mathrm{c}$.

ГавритухинИ.О. Эволюция восточноевропейских псевдопряжек // Культуры Евразийских степей второй половины I тыс. Н.э. (из истории костюма). Т. 2 / Отв. ред. Д.А. Сташенков. Самара: СОИМК, 2001. С. 31-86.

ГавритухинИ.О., ОбломскийА.М. Гапоновский клад и его культурно-исторический контекст: Коллективная монография (Раннеславянский мир. Вып. 3) / Ред. Г.Е. Афанасьев, И.П.Русанова. М.: ИА РАН, 1996. $298 \mathrm{c}$.

Гавритухин И.О., Иванов А.Г. Погребение 552 Варнинского могильника и некоторые вопросы изучения раннесредневековых культур Поволжья // Пермский мир в раннем средневековье: сборник научных статей (Archaeologia Permica. Вып. 1) / Отв. ред. А.Г. Иванов. Ижевск: УИИЯЛ УрО РАН, 1999. C. 99-159.

Генинг В.Ф. Тураевский могильник V в. н.э. (Захоронения военачальников) // Из археологии Волго-Камья / Отв. ред. А.Х. Халиков. Казань: ИЯЛИ КФАН СССР, 1976. С. 55-108.

Генинг В.Ф. Памятники у с. Кушнаренково на р. Белой (VI-VII вв. н.э.) // Исследования по археологии Южного Урала / Отв. ред. Р.Г. Кузеев. Уфа: ИИЯЛ БФАН СССР, 1977. С.90-135.

Генинг В.Ф. Хронология поясной гарнитуры I тысячелетия н.э. (по материалам могильников Прикамья // КСИА. Вып. 158. 1979. С. 96-106.

Генинг В.Ф. Так называемая «турбаслинская культура» в Башкирии // Новые археологические исследования на территории Урала / Отв. ред. Р.Д. Голдина. Ижевск: УдГУ, 1987. С. 81-102.

Голдина Р.Д. Истоки «дальнего импорта» в 
Приуралье // Известия Коми научного центра УpO РАН. № 2(10). 2012. С. 108-119.

Голдина Р.Д., ВодолагоН.В. Могильники неволинской культуры в Приуралье. Иркутск: ИГУ, 1990. $176 \mathrm{c}$.

ГолдинаР.Д., ПеревозчиковаС.А., Голдина E.B. Могильник VI-IX вв. у д. Верх-Сая в Кунгурской лесостепи (Материалы и исследования Камско-Вятской археологической экспедиции. Т. 19). Ижевск: УдГУ, 2018. 720 с.

Иванов B.A. Путями степных кочевий. Уфа: Башкирское кн. изд-во, 1984. 136 с.

Иванов В.A. Южное Приуралье в эпоху Великого переселения народов - археолого-географический контекст // Поволжская археология. 2017. №4(22). C. 8-23.

Казаков Е.П. О кушнаренковских памятниках на территории Татарии // Вопросы археологии Урала. Вып. 15 / Отв. ред. В.Е.Стоянов. Свердловск: УрГУ, 1981. С. 136-140.

Казаков Е.П. Коминтерновский II могильник в системе древностей эпохи Тюркских каганатов // Культуры евразийских степей второй половины І тыс. н.э. / Отв. ред. Д.А. Сташенков. Самара: СОИМК, 1998. С.97-150.

Казаков Е.П. Этнокультурная ситуация IVVII вв. н.э. в Среднем Поволжье // Finno-Ugrica. 2011. № 12-13. С. 8-39.

Казанский М.M. Пряжки раннесасанидской традиции в Северной Евразии // Первобытная археология. Человек и искусство. Сборник науч. трудов к 70-летию Я.А. Шера / Ред. В.В.Бобров, О.С. Советова. Новосибирск: ИАЭТ СО РАН, 2002. С. 193-197.

Ковалевская В.Б. Компьютерная обработка массового археологического материала из раннесредневековых памятников Евразии (Хронология Восточноевропейских древностей $\mathrm{V}$ IX вв. Вып. 2. Стеклянные бусы и поясные наборы). М.: ИА РАН, 2000. $361 \mathrm{c.}$

Красноперов А.А. Полихромные предметы с перегородчатой инкрустацией в Прикамье («догуннский» стиль перегородчатых инкрустаций) // Лесная и лесостепная зоны Восточной Европы в эпохи римских влияний и Великого переселения народов. Конференция 3 / Ред. А.М.Воронцов, И.О. Гавритухин. Тула: Гос. музей-заповедник «Куликово поле», 2012. С. 218-254.

$K$ проблеме городов Южного Урала эпохи средневековья: Коллективная монография / Сост. и науч. ред. Ф.А.Сунгатов; Уфа: Самрау, 2018. 335 c.

ЛевинаЛ.М. Этнокультурная история Восточного Приаралья I тысячелетие до н.э. - I тысячелетие н.э. М.: Восточная литература, 1996. $396 \mathrm{c}$.

МажитовН.А. Курганный могильник в деревне Ново-Турбаслы // Башкирский археологический сборник / Под ред. А.П.Смирнова, Р.Г.Кузеева. Уфа: ИИЯЛ БФАН СССР, 1959. C. 114-142.
Мажитов Н.А. Бахмутинская культура. Этническая история населения Северной Башкирии І тыс. н.э. М.: Наука, 1968. 162 с.

Мажитов Н.А. Южный Урал в VII-XIVвв. М.: Наука, 1977. 240 с.

Мажитов Н.А. Южный Урал в VI-VIII вв. // Археология СССР. Степи Евразии в эпоху средневековья / Отв.ред. тома С.А. Плетнева. М.: Наука, 1981. С. 23-28.

Мажитов Н.A. Отчет об итогах раскопок на Бирском могильнике в 1985 году. Уфа, 1986 // Научный архив МК ИИГУ БашГУ. Ф. 2. Д. 21.

МажитовН.А., СунгатовФ.А., СултановаА.Н. Сокровища древней Уфы. Уфа: ГУП «ГРИ Башкортостан», 2008. 112 с.

Матвеева Г.И. Шареевский могильник // Из истории Башкирии (дореволюционный период). Уфа: БашГУ, 1968. С. 5-20.

МатвееваГ.И. Лесная и лесостепная Башкирия во второй половине Ітыс. н.э. // Археология и этнография Башкирии. T.IV / Отв. ред. Ю.В.Бромлей, Р.Г. Кузеев. Уфа: БФАН СССР, 1971. С. 129-134.

МатвееваГ.И. Среднее Поволжье в IVVII вв.: именьковская культура: Учеб. пособие, 2-е изд., дополн. Самара: Самарский университет, 2004. 168 с.

Овсянников В.В. Истоки и типологические связи кушнаренковского и кара-якуповского комплексов вооружения // Курганы кочевников Южного Урала / Отв. ред. Б.Б. Агеев. Уфа: Гилем, 1995. С. 138-150.

Перескоков М.С. Пермское Предуралье в финале раннего железного века. Пермь: ПГНИУ, 2018. 320 c.

Пшеничнюк A.X. Уфимский курганный могильник // Археология и этнография Башкирии. Т. III / Отв. ред. Р.Г. Кузеев. Уфа: ИИЯЛ БФАН СССР, 1968. С. 105-112.

Скіба А.В. Поясні набори слов’ ян: геральдичний стиль. Київ: ІА НАНУ, 2016. 236 с.

СмирновА.П. Железный век Башкирии // Культура древних племён Приуралья и Западной Сибири / МИА. № 58. 1957. С. 5-113.

Султанова А.Н. Бирский могильник: историко-археологическое исследование. Диссертация ... канд. ист. наук: 07.00.06. Уфа, 2000. 202 с.

Сунгатов $Ф . A$. Турбаслинская культура (по материалам погребальных памятников VVIIIвв. н.э.). Уфа: Гилем, 1998. 169 с.

СунгатовФ.А. Волго-Уральский регион в эпоху Тюркских каганатов // Древнетюрский мир: история и традиции. Материалы одноименной науч. конф. Казань, 24-25 января 2001 г. Казань: Институт истории АН РТ, 2002. С. 25-32.

Сунгатов Ф.А. Южный Урал в период Великого переселения народов // Этнические взаимодействия на Южном Урале. Великое переселение народов: диалог культур. Материалы VIII Междунар. науч. конф. Челябинск: Гос. ист. музей Южного Урала, 2020. С. 66-83. 
Сунгатов Ф.А., Куфтерин В.В. Погребение с элементами поясного «геральдического» набора из могильника Чайка-1 // Уфимский археологический вестник. 2020. Вып.20. С.96-108. DOI: https://doi.org/10.31833/uav/2020.20.007

Торгоев А.И. Геральдический пояс с Верхнего Таласа // Археологические вести. 2005. № 12. C. 88-91.

ХайрединоваЭ.А. Обувные наборы V-VII вв. из Юго-Западного Крыма // Материалы по археологии, истории и этнографии Таврии. Вып. 10 / Ред.-сост. А.И.Айбабин. Симферополь: Таврия, 2003. С. $125-160$.
Gavritukhin I.O. Belt sets from Alanic graves: Chronology and cultural links // Belinskij A.B., HärkeH. Ritual, society and population at Klin-Yar (North Caucasus): Excavations 1994-1996 in the Iron Age to early medieval cemetery. Bonn: Habelt-Verlag, 2018. P. 49-96, 217-236, 241-244, 246-247, 255, 258 $259,262,272,278,279,281-283,289,292-294,297-$ $299,301,308,310-314,316,317,321-324,334,340$, 357-359, 371, 376, 378, 382, 387, 392, 394, 399, 401, 403, 407, 409, 412, pl. 5 .

\section{REFERENCES}

Aibabin, A.I. "Chronology of Crimean necropolises of the Late Roman and the Early Medieval periods", Materialy po arheologii, istorii i etnografii Tavrii. Vyp. 1 ("Materials on the archeology, history and ethnography of Tavria. Issue 1"). Simferopol, 1990. pp. 3-86, 174-241. (In Russ.)

Aibabin, A.I. 1999, Ethnic history of the Early Byzantine Crimea. Dar, Simferopol, 352 p. (In Russ.)

Akimova, M.S., Gening, V.F. 1960, Report on the research of archaeological sites near Kushnarenkovo village of the Bashkir ASSR in 1959. Archive of the IA $R A S$, no. 1953. Moscow. (In Russ.)

Ambrose,A.K. 1973, "Erdeli I., Oitozi E., Gening V. Das Greberfeld von Nevolino. Budapest: Kiadu Academy, 1969. 93 p., 26 figures in the text, 101 tables, 1 map, 2 plans", Soviet archaeology, no.2, pp. 288-298. (In Russ.)

Bader, O.N., Smirnov,A.P., Ageev, B.B., Vasyutkin, S.M., Vasiliev, I.B., Mazhitov, N.A., Matveeva, G.I., Morozov, Y.A., Pshenichnyuk,A.H., Sadykova, M.H., Stokolos, V.S. 1976, Archaeological map of Bashkiria. Nauka, Moscow, 264 p. (In Russ.)

Atavin,A.G. "Burials of the $7^{\text {th }}-$ early $8^{\text {th }}$ centuries in the Eastern Azov region", Kul'tury Evrazijskih stepej vtoroj poloviny I tysyacheletiya n.e. ("Cultures of the Eurasian steppes in the second half of the $1^{\text {st }}$ millennium AD"). Samara, 1996, pp. 208-264. (In Russ.)

Akhmerov, R.B. "Ufa burials of the $4^{\text {th }}-7^{\text {th }}$ centuries $\mathrm{AD}$ and their role in the ancient history of Bashkiria", Drevnosti Bashkirii ("Antiquities of Bashkiria"). Moscow, 1970, pp. 161-163. (In Russ.)

Belyavskaya, O.S. "On the study of the Early Medieval elite burial on the territory of Ufa", Novye materialy i metody arheologicheskogo issledovaniya: Ot kritiki istochnika $\mathrm{k}$ obobshcheniyu i interpretacii dannyh. Materialy V Mezhdunar. konf. molodyh uchenyh ("New ways and methods of archaeological research: from the criticism of sources to the generalization and interpretation of data. Proceedings of the $5^{\text {th }}$ International Conference of the Young Scientists'). Moscow, 2019, pp. 133-135. (In Russ.)

Belyavskaya, O.S. 2019, "«Nikolskoye finds» of the III-VII centuries in the forest-steppe Cis-Urals", Bulletin of the Moscow University, ser. 8, history, no. 4, pp. 144-159. (In Russ.)
Bogachev,A.V. 1992, Procedural and methodological aspects of archaeological dating (based on the belt fittings of the $4^{\text {th }}-8^{\text {th }}$ centuries from the Middle Volga region). Artefact, Samara, 208 p. (In Russ.)

Bulychev, N.I. 1902, Antiquities from Eastern Russia. Issue I. A.I.Mamontov's Printing Company, Moscow, 30 p. (In Russ.)

Bulychev, N.I. 1904, Antiquities from Eastern Russia. Issue II. Art Press Association, St. Petersburg, 15 p. (In Russ.)

Vasyutkin, S.M. Report on archaeological research in the Bashkir ASSR in 1966. Archive of IA RAS, no. 3242. Ufa, 1967 (In Russ.)

Vasyutkin, S.M. 1971, "On the periodization of the ethnic history of the population of Bashkiria in the Middle Ages ( $3^{\text {rd }}-13^{\text {th }}$ centuries)", Archeology and ethnography of Bashkiria, vol.4, pp.135-139. (In Russ.)

Gavrilova,A.A. 1965, Kudyrge necropolis as a source on the history of the Altai tribes. Moscow, Leningrad, Nauka, 144 p. (In Russ.)

Gavritukhin, I.O. "Evolution of East European pseudo-buckles", Kul'tury Evrazijskih stepej vtoroj poloviny I tys. n.e. (iz istorii kostyuma). T. 2 ("Cultures of the Eurasian steppes of the second half of the $1^{\text {st }}$ millennium $\mathrm{AD}$ (from the history of clothing). Vol.2”). Samara, 2001, pp. 31-86. (In Russ.)

Gavritukhin, I.O., Oblomsky,A.M. 1996, Gaponovo treasure and its cultural and historical context: A collective monograph (The Early Slavic World. Issue 3). IA RAS, Moscow, 298 p. (In Russ.)

Gavritukhin, I.O., Ivanov, A.G. "Grave no. 552 of the Varni necropolis and some problems of study of the early medieval cultures in the Volga region", Permskij mir v rannem srednevekov'e: sbornik nauchnyh statej (Archaeologia Permica. Vyp. 1) ("The Permian World in the Early Middle Ages: a collection of scientific papers (Archaeologia Permica. Issue 1)"). Izhevsk, 1999, pp. 99-159. (In Russ.)

Gening, V.F. "Turaevsky necropolis dated to the $5^{\text {th }}$ century AD (Burials of the military leaders)", $I z$ arheologii Volgo-Kam'ya ("Archeology of the VolgaKama region”). Kazan, 1976, pp. 55-108. (In Russ.)

Gening, V.F. "Archaeological sites near the village of Kushnarenkovo at the Belaya river $\left(6^{\text {th }}-7^{\text {th }}\right.$ AD)", Issledovaniya po arheologii Yuzhnogo Urala 
("Research on the archeology of the Southern Urals"). Ufa, 1977, pp.90-135. (In Russ.)

Gening, V.F. 1979, "Chronology of the belt fittings of the $1^{\text {st }}$ millennium $\mathrm{AD}$ (based on the artefacts from the burials in the Kama region", KSIA, iss. 158, pp.96-106. (In Russ.)

Gening, V.F. "The so-called "Turbasly culture" in Bashkiria", Novye arheologicheskie issledovaniya na territorii Urala ("New archaeological research on the territory of the Urals"). Izhevsk, 1987, pp.81-102. (In Russ.)

Goldina, R.D. 2012, "The origins of the "longdistance imports" in the Urals", Bulletin of the Komi Scientific Center of the Ural Branch of the Russian Academy of Sciences, no.2(10), pp.108-119. (In Russ.)

Goldina, R.D., Vodolago, N.V. 1990, Necropolises of the Nevolino culture in the Cis-Urals region. IGU, Irkutsk, 176 p. (In Russ.)

Goldina, R.D., Perevozchikova, S.A., \& Goldina, E.V. 2018, Necropolis of the $6^{\text {th }}-9^{\text {th }}$ centuries near Verh-Saya village in the Kungur forest-steppe. UdGU, Izhevsk, 720p. (In Russ.)

Ivanov, V.A. 1984, The ways of steppe nomads. Bashkir Publishing House, Ufa, 136 p. (In Russ.)

Ivanov, V.A. 2017, Southern Cis-Urals in the Migration Period, archaeological and geographical context, The Volga River Region Archaeology, no. 4(22), pp. 8-23. doi: 10.24852/pa2017.4.22.8.23 (In Russ.).

Kazakov,E.P. "About Kushnarenkovo archaeological sites on the territory of Tataria", Voprosy arheologii Urala. vyp. 15 ("Questions of the archeology of the Urals, iss. 15”). Sverdlovsk, 1981, pp. 136-140. (In Russ.)

Kazakov,E.P. "Kominternovsky II necropolis in the system of antiquities of the era of the Turkic Khanates", Kul 'tury evrazijskih stepej vtoroj poloviny I tys. n.e ("Cultures of the Eurasian steppes of the second half of the $1^{\text {st }}$ millennium AD"). Samara, 1998, pp. 97-150. (In Russ.)

Kazakov, E.P. 2011, Ethnocultural situation during the $4^{\text {th }}-7^{\text {th }}$ centuries AD in the Middle Volga region, Finno-Ugrica, no. 12-13, pp. 8-39. (In Russ.)

Kazansky, M.M. "Buckles of the Early Sasanian tradition in Northern Eurasia", Pervobytnaya arheologiya. Chelovek i iskusstvo. Sbornik nauch. trudov k 70-letiyu Y.A. Shera ("Prehistoric archaeology. Man and art. A collection of scientific papers to the 70th anniversary of the birth of Y.A. Sher"'). Novosibirsk, 2002, pp. 193-197. (In Russ.)

Kovalevskaya, V.B. 2000, Computer processing of the mass archaeological material from the early Medieval sites of Eurasia (Chronology of Eastern European antiquities of the $5^{\text {th }}-9^{\text {th }}$ centuries. Vol. 2. Glass beads and belt fittings). IA RAS, Moscow, 361 p. (In Russ.)

Krasnoperov, A.A. "Polychrome objects with cloisonné (inlay) found in the Kama region ("pre-Hunnic" style of cloisonné (inlay))", Lesnaya i lesostepnaya zony Vostochnoj Evropy v epohi rimskih vliyanij $i$ Velikogo pereseleniya narodov. Konferenciya 3 ("Forest and forest-steppe zones of Eastern Europe in the era of
Roman influences and in the Great Migration period. Conference 3"). Tula, 2012, pp. 218-254. (In Russ.)

Sungatov,F.A., Sultanova,A.N., \& Bakhshieva,A.K., Mukhametdinov, V.I., Ruslanova, R.R., Ruslanov, E.V. 2018, To the problem of the Southern Ural cities in the Middle Ages: A collective monograph. Samrau, Ufa, 335 p. (In Russ.)

Levina, L.M. 1996, Ethnocultural history of the Eastern Aral Sea region in the $1^{\text {st }}$ millennium BC$1^{\text {st }}$ millennium $A D$. Moscow, Vostochnaya literatura RAN, 396 p. (In Russ.)

Mazhitov, N.A. "Barrow necropolis in the village of Novo-Turbasly", Bashkirskij arheologicheskij sbornik ("Bashkir archaeological collection of papers"). Ufa, 1959, pp. 114-142. (In Russ.)

Mazhitov, N.A. 1968, Bakhmutinskaya culture. Ethnic history of the population of the Northern Bashkiria in the $1^{\text {st }}$ millennium AD. Nauka, Moscow, $162 \mathrm{p}$. (In Russ.)

Mazhitov, N.A. 1977, The Southern Urals in the $7^{\text {th }}-14^{\text {th }}$ centuries. Nauka, Moscow, 240 p. (In Russ.)

Mazhitov, N.A. "The Southern Urals in the $6^{\text {th }}-8^{\text {th }}$ centuries", Arheologiya SSSR. Stepi Evrazii v epohu srednevekov'ya ("Archeology of the USSR. Steppes of Eurasia in the Middle Ages"). Moscow, 1981, pp. 23-28. (In Russ.)

Mazhitov, N.A. Report on the results of archaeological excavations at the necropolis of Birsk in 1985. Ufa, 1986 (In Russ.)

Mazhitov, N.A., Sungatov, F.A., \& Sultanova,A.N. 2008, Treasures of ancient Ufa. GUP "GRI Bashkortostan", Ufa, 112p. (In Russ.)

Matveeva, G.I. "Shareevsky necropolis", Iz istorii Bashkirii (dorevolyucionnyj period) ("From the history of Bashkiria (pre-revolutionary period)").Ufa, 1968, pp. 5-20. (In Russ.)

Matveeva, G.I. 1971, "Forest and forest-steppe Bashkiria in the second half of the $1^{\text {st }}$ millennium AD", Archeology and ethnography of Bashkiria, vol. 4, pp. 129-134. (In Russ.)

Matveeva, G.I. 2004, The Middle Volga region in the $4^{\text {th }}-7^{\text {th }}$ centuries: Imenkovo culture. Samara University, Samara, 168 p. (In Russ.)

Ovsyannikov, V.V. "The origins and typological parallels between the Kushnarenkovo and Kara-Yakupovo armament assemblages", Kurgany kochevnikov Yuzhnogo Urala ("Barrows of nomads in the Southern Urals"). Ufa, 1995, pp. 138-150. (In Russ.)

Pereskokov,M.S. 2018, Permian Cis-Urals at the end of the Early Iron Age. PGNIU, Perm, 320 p. (In Russ.)

Pshenichnyuk,A.H. 1968, "Ufa barrow necropolis", Archeology and ethnography of Bashkiria, vol. 3, pp. 105-112. (In Russ.)

Skiba,A.V. 2016, Belt fittings of the Slavs: heraldry style. IA NASU, Kyiv, 236p. (In Russ.)

Smirnov, A.P. 1957, "The Iron Age in Bashkiria", MIA, no. 58, pp. 5-113. (In Russ.)

Sultanova,A.N. 2000, Birsk necropolis: historical and archaeological research. Dissertation ... Candidate of Historical Sciences: 07.00.06. Ufa, 202p. (In Russ.) 
Sungatov, F.A. 1998, The Turbasly culture (based on the assemblages from the burials of the $5^{\text {th }}-8^{\text {th }}$ centuries $A D$ ). Gilem, Ufa, 169p. (In Russ.)

Sungatov, F.A. "The Volga-Ural region in the era of the Turkic Khanates", Drevnetyurskij mir: istoriya $i$ tradicii. Materialy odnoimennoj nauch. konf. Kazan', 24-25 yanvarya 2001 g. ("Ancient Turkic world: history and traditions. Proceedings of the scientific conference. Kazan, January 24-25, 2001"). Kazan, 2002, pp. 25-32. (In Russ.)

Sungatov, F.A. "Southern Urals in the Great Migration period", Etnicheskie vzaimodejstviya na Yuzhnom Urale. Velikoe pereselenie narodov: dialog kul 'tur. Materialy VIII Mezhdunar. nauch. konf. ("Ethnic interactions in the Southern Urals. The Great Migration: dialogue between cultures. Materials for the $8^{\text {th }}$ International Scientific Conference"). Chelyabinsk, 2020, pp. 66-83. (In Russ.)

Sungatov, F.A., Kufterin, V.V. 2020, A burial with "heraldic" belt fittings from Chaika-1 necropolis,
Ufa Archaeological Herald, vol.20, pp.96-108. doi: 10.31833/uav/2020.20.007. (In Russ.)

Torgoev, A.I. 2005, Heraldic belt from the Upper Talas, Archaeological news, no.12, pp.88-91. (In Russ.)

Khayredinova,E.A. 2003, "Shoe sets of the $5^{\text {th }}$ $7^{\text {th }}$ centuries from the South-Western Crimea", $M a$ terials on archeology, history and ethnography of Tavria, iss. 10, pp. 125-160. (In Russ.)

Gavritukhin, I.O. "Sets of belts from Alan graves: chronology and cultural relations", BelinskyA.B., Herke H. Ritual, society and population in Klin-Yar (North Caucasus): Excavations 1994-1996. from the Iron Age to the Early Medieval cemetery. Bonn, 2018. p. 49-96, 217-236, 241-244, 246-247, 255, 258-259, $262,272,278,279,281-283,289,292-294,297-299$, $301,308,310-314,316,317,321-324,334,340$, $357-359,371,376,378,382,387,392,394,399,401$, $403,407,409,412$, pl. 5 .

\section{Сведения об авторе}

Белявская Ольга Сергеевна, независимый исследователь, Российская Федерация, Московская область, г. Мытищи. E-mail: krapacheva.olya@mail.ru, ORCID: 0000-0003-2365-0877

\section{Information About the Author}

Olga S. Belyavskaya, independent researcher, Russian Federation, Moscow Oblast, Mytishchi. E-mail: krapacheva.olya@mail.ru, ORCID: 0000-0003-2365-0877 